\title{
An initial map of chromosomal segmental copy number variations in the chicken
}

\author{
Xiaofei Wang ${ }^{* 1}$, Samuel Nahashon², Tromondae K Feaster ${ }^{1}$, Ann Bohannon-Stewart ${ }^{1}$ and Nathaniel Adefope ${ }^{\wedge}$
}

\begin{abstract}
Background: Chromosomal segmental copy number variation (CNV) has been recently recognized as a very important source of genetic variability. Some CNV loci involve genes or conserved regulatory elements. Compelling evidence indicates that CNVs impact genome functions. The chicken is a very important farm animal species which has also served as a model for biological and biomedical research for hundreds of years. A map of CNVs in chickens could facilitate the identification of chromosomal regions that segregate for important agricultural and disease phenotypes.

Results: Ninety six CNVs were identified in three lines of chickens (Cornish Rock broiler, Leghorn and Rhode Island Red) using whole genome tiling array. These CNVs encompass $16 \mathrm{Mb}$ (1.3\%) of the chicken genome. Twenty six CNVs were found in two or more animals. Whereas most small sized CNVs reside in none coding sequences, larger CNV regions involve genes (for example prolactin receptor, aldose reductase and zinc finger proteins). These results suggest that chicken CNVs potentially affect agricultural or disease related traits.

Conclusion: An initial map of CNVs for the chicken has been described. Although chicken genome is approximately one third the size of a typical mammalian genome, the pattern of chicken CNVs is similar to that of mammals. The number of CNVs detected per individual was also similar to that found in dogs, mice, rats and macaques. A map of chicken CNVs provides new information on genetic variations for the understanding of important agricultural traits and disease.
\end{abstract}

\section{Background}

Genomic variations within a species may involve changes as small as a single nucleotide to as large as microscopically visible chromosome segments, even whole sets of chromosomes. While microscopic genome variations were studied in cytogenetic laboratories for a long time, the readily availability of DNA sequencing technology and high throughput approach have popularized analysis on single nucleotide polymorphism (SNP) and microsatellites. It was not until recently that genome variation involving intermediate DNA segments, called segmental copy number variation $(\mathrm{CNV})$, was recognized. This type of genome variation involves submicroscopic insertion, deletion, segmental duplication and complex changes of greater than $1 \mathrm{~kb}$ to several $\mathrm{Mb}$ in size [1-3]. Whole genome scanning studies for $\mathrm{CNV}$ have been conducted

\footnotetext{
* Correspondence: xwang@tnstate.edu

1 Department of Biological Sciences, Tennessee State University, 3500 John A. Merritt Blvd, Nashville, TN 37209, USA

$\wedge$ Deceased

Full list of author information is available at the end of the article
}

extensively in humans [4-10], chimpanzees [11,12], dogs $[13,14]$, mice [15-18], rats [19] and swine [20]. Although several chicken CNV loci have been studied in a case-bycase manner [21,22], CNV in birds has received little attention. To our understanding, few publications are available describing whole genome CNV studies in birds [23].

Since its domestication 8,000 years ago, the chicken has provided table eggs, meat and ritual values to human society. Over the last 100 years, the chicken has also served as a model organism for fundamental biological and biomedical studies [24]. The first examples of oncogene and viral induced tumor were demonstrated in the chicken [25]. The B-lymphocytes were first identified in chickens. Spontaneous chicken mutants, such as the dwarf $[26,27]$ and the retina degeneration [28], have provided rich information regarding particular gene functions. The regulation of chicken ovalbumin expression was studied extensively to elucidate the mechanism of eukaryotic transcription control [29] and steroid hormone actions $[30,31]$. Because of the historical, biomedi- 
cal and agricultural importance, evolutionary distance and readily availability, the chicken is the leading species among farm animals in the development of genomics tools and resources, including the chicken genome assembly [32], genetic variation map of single nucleotide polymorphism [24,33], collections of comprehensive expressed sequence tags (EST) [34-37] and DNA microarray [38-40].

Distinct from mammalian genomes, typical avian genomes are composed of several large chromosomes and a group of microchromosomes that are indistinguishable microscopically with conventional karyotyping techniques [41,42]. The chicken genome has 1.2 billion base pairs on 39 pairs of chromosomes, including a pair of sex chromosomes ZZ for males and ZW for females $[43,44]$. Despite that the chicken genome is one third of a typical mammalian genome in DNA content, it was predicted to have a similar number of genes [37]. Thus, it would be conceivable that the chicken has reduced intergenic spaces and reduced repetitive sequence content. How the compacted genomes vary in chromosomal segmental copy number and how these variations affect important agricultural and biomedical traits are of great interest. Here we provide a snapshot of CVNs in the chicken genome.

\section{Results and Discussion Mapping of CNVs in chickens}

NimbleGen whole genome tiling arrays containing 385,000 probes were used to analyze chicken CNVs. Four broilers (Cornish Rock, 2 males and 2 females), four Leghorns ( 2 males and 2 females) and two Rhode Island Reds (males) were analyzed with array comparative genome hybridization (aCGH). One additional male broiler DNA was used as a reference for all hybridizations. CNVs were identified by comparing ratio between the test and the reference and all $\mathrm{CNV}$ loci were visually inspected on aCGH data plots (Additional file 1, Fig. S1). We identified 96 high confidence or suggestive CNVs. When CNV signals in two or more animals overlapped on a chromosome, they were considered to be high confidence CNV. On average, seventeen CNVs were called in each bird.

These CNVs were found on chicken chromosomes (GGA) 1-8, 10-18, 20, 22-27, and Z (Table 1 and Additional file 2, Table S1). Due to poor probe coverage, data on $\mathrm{W}$ chromosome were removed from analysis. The 96 CNVs encompassed $16 \mathrm{Mb}$, which is about $1.34 \%$ of the entire chicken genome. Among the $96 \mathrm{CNV}$ loci, forty six loci were non-coding sequences $(5.1 \mathrm{Mb})$.

There were 26 high confidence CNVs that were observed at least in two birds (Table 1). Among these high confidence loci, eleven loci involve non-coding sequence only, which sum up to $525 \mathrm{~kb}$. The remaining 15 loci occupied about $1.5 \mathrm{Mb}$, involving one or more coding sequences.

Variations at locus 13 (chr4:88,897,639-89,072,982) on GGA4 (Table 1) appear to be complex. When compared with the reference, three birds showed loss of 150-170 kb, while two other birds showed a gain of $112 \mathrm{~kb}$ and $172 \mathrm{~kb}$. Locus 10 on GGA2 has three clearly different alleles, one of which was a gain of $300 \mathrm{~kb}$ and the other was a loss of $20 \mathrm{~kb}$ region and the third allele was without gain or lost. However, visual inspection of corresponding aCGH plots revealed that several other samples may also have copy gains (Additional file 3, Fig. S2 A).

In our dataset, two CNV calls were made for chromosome 25. One of the calls appears to be a gain of an entire chromosome 25 in bird \#5849 (Additional file 2, Table S1), but no obvious visual abnormality of the bird was observed. The other CNV involves the first 10-kb region of the chromosome assembly.

The majority of the high confidence CNVs was shared across breeds, suggesting their relative "ancient" origin. Some high confidence CNVs were specific to individual breeds. Whether they are breed-specific requires further evaluation of a much larger sample size. It is not clear whether these putative private CNVs contribute to breed specific biology. Fewer high confidence CNVs were found in Rhode Island Reds when compared with other strains evaluated. This may be attributable to the small number of animals analyzed, small founder population and/or population diversity.

Seventy CNVs, which encompassed $14 \mathrm{Mb}$, were observed only once in our data set (Additional file 2, Table S1). Of the seventy CNVs, twenty seven CNVs involved only non-coding sequences $(1.8 \mathrm{Mb})$. Twenty nine CNVs showed loss of DNA while the rest showed gains of DNA. The majority (62\%) of CNVs with DNA loss were non-coding sequences. In contrast, the majority (80.5\%) of CNVs with gain of DNA involve coding sequences. In addition, sizes in CNVs of DNA loss tend to be smaller (mean $43.2 \mathrm{~kb}$ and median $30 \mathrm{~kb}$ ) compared with that of DNA gain (mean $313 \mathrm{~kb}$ and median $67 \mathrm{~kb}$ ).

Although probes assigned to unknown chromosome locations were excluded from CNV calls, an ambiguous segment on GGA 20 (chr20_random in chicken genome draft 2.1 at UCSC genome database) is noteworthy. The entire segment was $72 \mathrm{~kb}$ according to the genome assembly. Several ESTs and mRNAs were mapped to this segment. Data from aCGH strongly support that this region be assigned to $\mathrm{W}$ chromosome [45]: All female birds showed gain of copies with high scores, when compared with the reference.

\section{Quantitative PCR analysis and CNV validation}

Real time quantitative PCR (qPCR) was performed to validate aCGH data at five loci. Two of the five loci (e. g. 
Table 1: High confidence CNVs in chickens

\begin{tabular}{|c|c|c|c|c|c|c|c|c|}
\hline \multirow[t]{2}{*}{ Locus ID } & \multirow[t]{2}{*}{ Chromosome } & \multirow[t]{2}{*}{ Start position* } & \multirow[t]{2}{*}{ Size (bp) } & \multirow[t]{2}{*}{ Gene } & \multicolumn{3}{|l|}{ Status" } & \multirow{2}{*}{$\begin{array}{c}\text { Number of } \\
\text { observations }\end{array}$} \\
\hline & & & & & Broiler & Leghorn & $\mathbf{R I R}^{\dagger}$ & \\
\hline 1 & 1 & 4015022 & 47654 & LOC419112 & loss & loss & loss & 6 \\
\hline 2 & 1 & 44980061 & 80399 & Non-coding & loss & loss & & 7 \\
\hline 3 & 1 & 48005486 & 34931 & Non-coding & gain & & & 3 \\
\hline 4 & 1 & 59885173 & 32693 & CHRM2 & & loss & & 2 \\
\hline 5 & 1 & 165880299 & 112347 & ZFR, IL-3 & gain & gain & & 4 \\
\hline 6 & 2 & 40647961 & 39933 & Spliced ESTs & & gain & loss & 2 \\
\hline 7 & 2 & 95665092 & 10297 & Non-coding & gain & gain & & 4 \\
\hline 8 & 2 & 97295434 & 44839 & Non-coding & gain & gain & & 5 \\
\hline 9 & 2 & 134727846 & 102330 & MGC24975(SZD6) & gain & gain & & 3 \\
\hline 10 & 2 & 154562776 & 299829 & SCRIB & loss & gain & & 2 \\
\hline 11 & 3 & 113612615 & 40053 & MRPL19, & loss & & loss & 2 \\
\hline 12 & 4 & 62172811 & 12364 & Non-coding & loss & & loss & 2 \\
\hline 13 & 4 & 88897639 & 175343 & RHACD8 & gain & loss & loss & 5 \\
\hline 14 & 4 & 89602897 & 42219 & Non-coding & & loss & & 3 \\
\hline 15 & 5 & 22120222 & 92556 & Non-coding & & loss & & 3 \\
\hline 16 & 6 & 12150334 & 84982 & Non-coding & & loss & loss & 3 \\
\hline 17 & 10 & 125113 & 32851 & olfactory receptor $6 \mathrm{k} 2$ & gain & gain & & 2 \\
\hline 18 & 11 & 2670295 & 14897 & Non-coding & gain & & & 3 \\
\hline 19 & 12 & 15208 & 77317 & Non-coding & loss & & & 2 \\
\hline 20 & 13 & 2722503 & 60308 & EST & loss & & loss & 3 \\
\hline 21 & 16 & 200114 & 12820 & Zinc finger protein & loss & loss & & 2 \\
\hline 22 & 16 & 270019 & 162832 & HLA class I antigen & loss & loss & & 2 \\
\hline 23 & 17 & 567532 & 57890 & PRF1 & gain & & & 2 \\
\hline 24 & Z & 9965426 & 192201 & PRLR & loss & loss & & 2 \\
\hline 25 & Z & 71975037 & 142814 & CDKN2A, MTAP & loss & loss & loss & 3 \\
\hline 26 & Z & 73495364 & 29964 & Non-coding & gain & gain & & 2 \\
\hline
\end{tabular}

Note: *, the start position of the CNV was based on 2006 chicken genome assembly. \#, gain or loss was assigned based on common reference DNA from one broiler bird (\#6281). $†$, Rhode Island Red.

PCCA, THRSP) served as references of no variation in copy number, while three loci were CNV detected with aCGH. The PCCA locus encodes propionyl coenzyme A carboxylase. Analysis of chicken genome assembly indicated that a single copy of this gene exists in a haploid genome. Two copies of THRSP genes exist in chickens [46]. The qPCR results for PCCA locus showed minimal variations among 20 birds (including 11 birds examined with aCGH). We attribute these variations to random errors, including DNA dilution error. Similar qPCR results were obtained for THRSP locus in 23 birds (including 20 birds examined for PCCA), which also showed minimal variations among birds except that two birds appeared to have lost copies (data not shown). Three CNV loci (e. g. locus 13:CD8 $\alpha-R H A C D$, locus 24:PRLR, and a suggestive locus $A K R 1 B$ ) were examined twice: once estimated with standard curve method (Fig. $1 \mathrm{~B}, \mathrm{C}, \mathrm{D})$ in 20 birds and once with $2^{-\mathrm{CCt}}$ method in 23 birds (not shown). Results of the two separate qPCR assays were concordant. F-tests were performed to determine whether copy numbers detected with $\mathrm{qPCR}$ have the same variance between the reference locus and CNV loci. Results indicate that all three CNV loci had greater variance than the references $(P<0.05$ for $P R L R$ locus and $P<0.01$ for $A K R 1 B$ and $R H A C D 8)$, suggesting the three loci were truly CNV. 
Locus 13 involves $R H A C D 8$, which was reported to have variable copy numbers among different breeds of chickens. Our qPCR data indicated relative copy number of RHACD8 locus was highly variable among chickens. Birds with the highest copy number had seven times as much as those with the lowest copy number.

Locus 24 involves prolactin receptor gene (PRLR). In our aCGH assay, this locus was identified in 2 females. Another bird appeared to be false negative, because visual inspection of aCGH plots revealed likely shifting of the $\log 2$ ratio (Additional file 3, Fig. S2 B). Subsequent qPCR

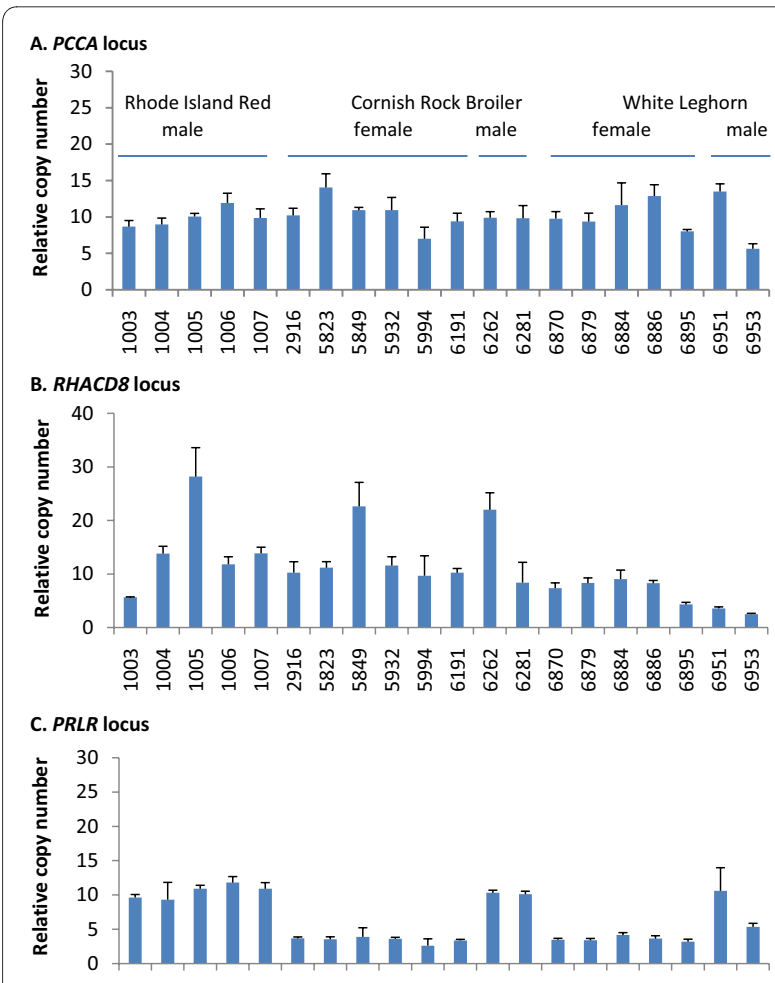

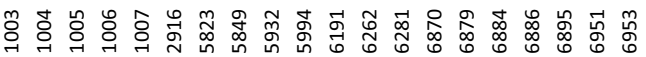

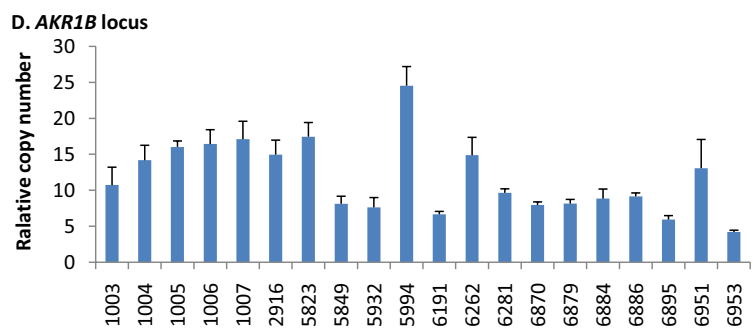

Figure 1 Quantitative PCR analysis of CNVs in 20 birds. DNA samples were diluted to $10 \mathrm{ng} / \mu \mathrm{l}$ and the conecentrations were meassured with Nanodrop spectrophotometer. Relative copy number was obtained by comparing threshold cyles of test DNA with a reference DNA that was serial diluted to $80,20,10$ and $2.5 \mathrm{ng} / \mu \mathrm{l}$. One unit of relative copies is the amount in $1 \mathrm{ng}$ of reference DNA. Values represent mean $\pm S D$ of four reactions. Data were not normalized to the reference locus and copy number was not rounded. Numbers on $\mathrm{x}$-axis are bird ID. analysis showed that all female birds have a single copy, and males showed 3 or 4 copies. Since PRLR is located on GGA Z, males are expected to have two copies per cell, whereas females have one copy should there be no CNV. However, $X^{2}$ tests indicated that the relative copy number ratio were 3:1 between males and females (Fig. 1C). It appeared that the male chicken \# 6953 did not have three folds the copy number of females. However, after DNA concentration correction, its relative copy number was the same as other males. Results of the separate qPCR assay with $2^{-\Delta \mathrm{Ct}}$ method agreed with this notion. The sex specific CNV at this locus can be explained by the industrial practice, as recently reported by Elferink [47]. A sexlinked late feathering allele $K$ containing 2 copies of PRLR has been introduced to commercial flocks and used widely for sexing hatchlings. This $K$ allele is incomplete dominant to the early feathering $k^{+}$allele containing one copy of PRLR. One of our bird suppliers crosses $k^{+} k^{+}$ males with $K W$ females, such that progeny females are early feathering $k^{+} \mathrm{W}$ containing one copy of $P R L R$, while the male progeny are late feathering $K k^{+}$containing three copies of PRLR.

The CNV locus on GGA 1, involving aldo-keto reductase 1B (Additional file 1, Table S1, AKR1B1 locus, chr1:64280187-64310165), was first identified as a suggestive $\mathrm{CNV}$ found in only one bird with a gain of copy. A qPCR assay showed that the variation in copy number was far more frequent (Fig. 1D) than it appeared in the aCGH: All Leghorn chickens had the least copies (presumably two copies) and all Rhode Island Reds doubled that figure, while Cornish Rock broilers have variable numbers from 2 to 7 copies. Visual inspection of this locus in aCGH plots did not reveal convincingly significant variations.

\section{Complexity of chicken CNVs}

In order to understand genomic organizations of DNA sequences involved in CNV, we mapped DNA sequences that are similar to the ones in CNV regions by BLAT search. This mapping revealed the organization complexity of some CNVs. For example, according to chicken genome build 2.1, locus 17 on GGA 10 showed duplication of various blocks in a 90-kb region (Fig. 2). This locus contains at least 6 copies olfactory receptor-like sequences, organized in grossly three larger repeating units in the same orientation. Blocks of several hundred to several thousand base pairs are highly conserved ( $>95 \%$ identity in nucleotide sequences) among these repeating units. However, the relative positions of these blocks were shuffled to different places.

The $C D 8 \alpha$ locus on GGA 4 is also organized in a complex way. Although it is known to be polymorphic among breeds [48], we did not anticipate such complex and 


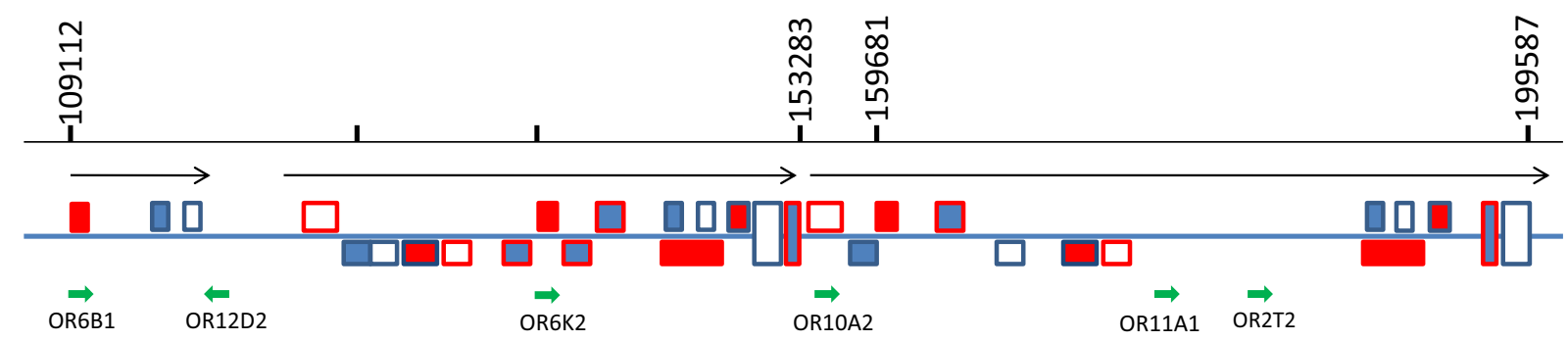

Figure 2 Organization of CNV region at locus 17 located on GGA 10 (Chr10: 125113-157964). A block of sequence (Chr10:125051-149999) was aligned with chicken genome assembly build 2.1 using BLAT algorithm at UCSC genome database. Numbers at the top of the graph represent nucleotide positions in the chicken genome assembly. Long arrows indicate higher order repeat organization and orientation. Short green arrows indicate orientation and location of human olfactory receptor homologs aligned to GGA 10. Symbols of the same style (line color and fillings) on the same side of the blue line represent sequence blocks sharing $>95 \%$ identity.

extensive variations as revealed by qPCR. Other loci examined also show more or less complexity.

\section{Functional implications of chicken CNVs}

Among the high confidence CNV loci, at least 15 loci involve partial or entire functional genes. Many of these functional genes have paralogs in the chicken genome. For example, CNV locus 5 on GGA 1 (Chr1: 165880299166002720) encodes a zinc finger RNA binding protein (ZFR). In the chicken, a second copy of $Z F R$ is located on Z-chromosome (chrZ: 9,104,112-9,144,261). Locus 17 (chr10: 125113-157964) involves an olfactory receptor 6K1 (OR6K1)-like sequence.

The CNV at CHRM2 locus (locus 4) was observed in two of the Leghorn birds. CHRM2 is one of the five muscarinic acetylcholine receptor genes that play important roles in numerous physiological functions including higher cognitive processes such as memory and learning [49]. EST and other sequence data indicate that the chicken CHRM1, 4 and 5 are located on chromosome 5, while CHRM2 and 3 are mapped to chromosomes 1 and 3 respectively. Our aCGH data suggest the loss of CHRM2 copies in Leghorn chickens. Analysis of chicken whole genome assembly has not found any evidence that CHRM2 locus involves a recent duplication. Thus, deletion of CHRM2 is more likely the scenario in the Leghorn birds.

According to the May 2006 chicken (Gallus gallus) v2.1 draft assembly, the chicken $A K R 1 B$ locus contains 4 consecutive copies of $A K R 1 B$ organized head-to-tail. Although all copies appear to be transcribed since ESTs were found for all of them, the telomere-proximal copy appears to be more actively transcribed, as evidenced by the greater number of ESTs found for this copy. The four $A K R 1 B$ copies share $80-92 \%$ amino acid residues. However, the telomere-proximal two copies are less similar from each other as well as from the two centromere- proximal copies in intron sequences. The two centromere-proximal genes contain large blocks of sequences similar to each other, including introns. In vertebrates, each species has several $A K R 1 B s$ that are expressed in most tissues [50]. The AKR $1 \mathrm{~B}$ subfamily catalyzes the reduction of aldehydes [51]. Members of aldose reductase (AKR1B7, AKR1B10) may regulate fatty acid synthesis [52,53].

An EST was found to be derived from CNV locus 13. The sequence have been predicted to be a CD8 $\alpha$ - like messenger RNA -RHACD8, which was shown to be expressed in spleen [48]. We seek to determine whether the copy number variation could affect the level of RHACD 8 transcript. Spleen RNA levels of RHACD 8 and $C D 8 \alpha$ were examined in five broiler and five Leghorn females with RT-qPCR in two separate experiments (one with standard curve method and one with $2^{-\Delta \mathrm{Ct}}$ method, Fig. 3). RNA levels determined with $2^{-\Delta C t}$ method were highly correlated with those determined with standard curve method $(\mathrm{r}=0.88$ for $R H A C D 8$ and $\mathrm{r}=0.96$ for $C D 8 \alpha)$. Glyceraldehyde 3-phosphate dehydrogenase $(\mathrm{GAPDH})$ and $\beta$-actin mRNAs were examined as controls. Levels of $\beta$-actin mRNA varied remarkably among these chickens (data not shown). GAPDH mRNA levels were less variable (Fig. 3B), though bird \# 5994 showed much higher level of GAPDH transcript. CD $8 \alpha$ mRNA level appeared to be correlated with the level of $R H A C D 8$ transcripts $(\mathrm{r}=0.64$, or 0.56$)$, at a marginal statistical significance $(P=0.045$ or 0.08$)$. But there was no evidence of correlation between levels of RHACD 8 transcript and DNA copy number $(P>0.05$, Fig. 3$)$.

\section{Comparative genomics of chicken CNVs}

Since the platforms for CNV detection vary from species to species, much of the information cannot be compared directly across species. However, similarities can be found among studies using species-specific NimbleGen 


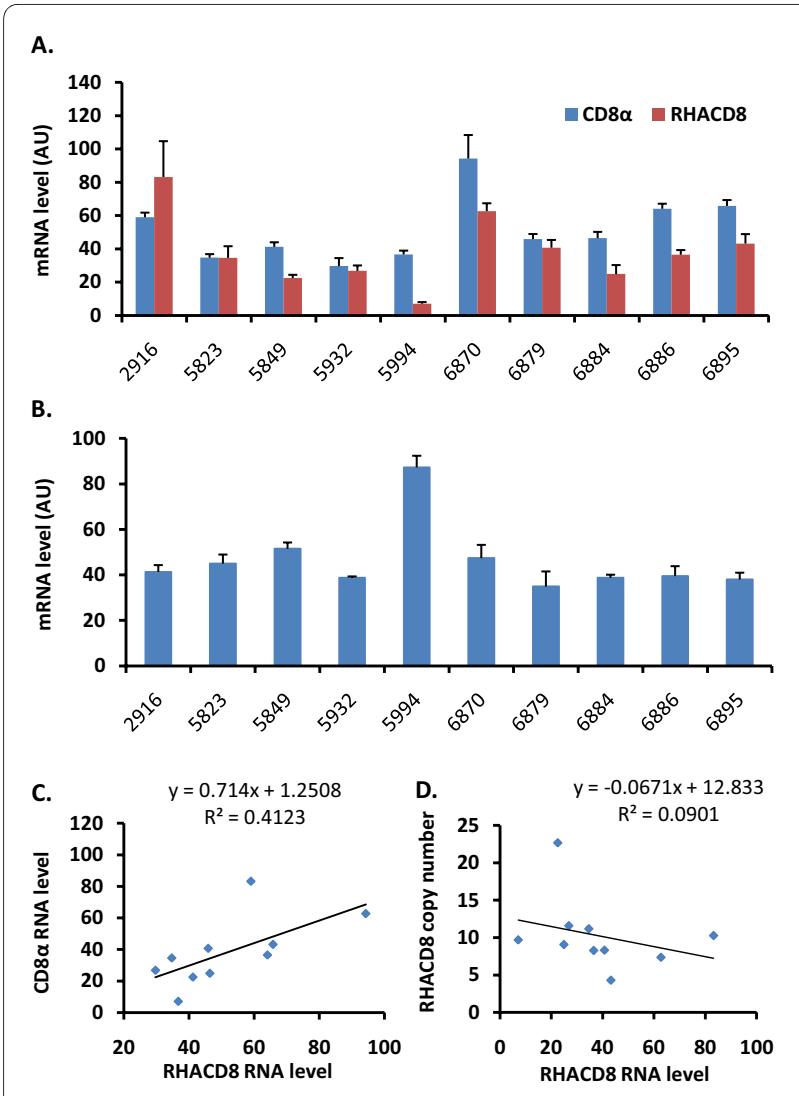

Figure 3 Relationship between copy number and transcript levels at RHACD8 locus. (A) Plot of spleen CD8a and RHACD 8 mRNA levels. Spleen RNA samples were isolated from adult broilers and Leghorns. (B) Plot of GAPDH mRNA levels in spleen of the same 10 chickens. (C) Pearson correlation between CD8a and RHACD 8 mRNA levels. (C) Pearson correlation between RHACD 8 mRNA level and of RHACD8 DNA copy number.

tiling arrays $[13,16,19,54]$. The NimbleGen mammalian arrays usually have a greater median probe space $(5 \mathrm{~kb})$ than the chicken array $(2.6 \mathrm{~kb})$. Accordingly, the average $\mathrm{CNV}$ sizes detected in mammals are larger than in chickens. However, the CNV calls in each individual are comparable among mouse, dog, and rhesus macaques [54]. Because the human genome was studied more extensively, up to $18.8 \%$ of human genome have been found in $\mathrm{CNV}$ regions [55]. Lower CNV coverage was found in other species. Our current data showed that chicken DNA sequences residing in CNV regions account for $1.34 \%$ of the genome, similar to that found in rat [19]. However, it is likely a significant underestimation of real CNVs in chickens, since a limited number of individuals have been surveyed. Furthermore, due to the incompleteness of the chicken genome assembly, a significant portion of the genome was not surveyed. The entire W chromosome was excluded from the analysis, and all probes that were assigned to ChrUn and chromosomerandom were also excluded.
Out of thirteen chicken-turkey CNVs reported by Griffin et al, [23], three loci overlapped with our high confidence CNVs and four loci overlapped with our CNVs of single observation. These data suggest that some of our single observations are true CNVs. The overlapping loci have size disagreement between Griffin's and our study, possibly due to the use of different references. Red jungle fowl was used as the reference by Griffins et al, while a Cornish Rock broiler bird was used as the reference in our study. The discrepancy may be attributable to nonrecurrent rearrangement. Apparently, larger populations need be examined to obtain a comprehensive picture of chicken CNV.

It is conceivable that lost DNA segments tend to be small in size and non-coding, while large $\mathrm{CNV}$ regions tend to emerge from gain of DNA and involve more functional genes, because large segment loss may be detrimental when these alleles are homozygous. Similar observations were also found in other species $[2,56]$. A significant number of CNVs involves members of paralogs. This can be explained by the fact that paralogous genes may compensate for lost copies. Similarly, a significant enrichment of CNVs in segmental duplications was found in the mouse [18].

It appeared that aCGH method tends to report larger segments being involved in the duplication/deletion than they really are. For example, the aCGH reported the involvement of $190 \mathrm{~kb}$ in the duplication of the $K$ locus on $\mathrm{Z}$ chromosome. Detailed studies by Elferink et al [47] showed this duplication involves only $176 \mathrm{~kb}$. This discrepancy is consistent with recent report that most CNVs are smaller in size than revealed by larger probe spacing [57].

It is of major interest to map the impact of CNVs in relation to disease, immunity, and agricultural traits. It has been shown that some CNVs contribute to phenotypic variations while others are amenable for genomewide association study for their influence on genetic disease or disease susceptibility. Nevertheless, large amount of putatively functional sequences, including protein coding sequences and conserved non-coding sequences, fall within or flank CNVs. In humans, although most CNVs were detected in apparently "healthy" individuals, many CNVs may have subtle, quantitative or late-onset phenotypic implications [58]. Functional attributes of the currently known CNVs are remarkably enriched in genes involved in environmental molecular interactions, including cytochrome p450 genes, immunoglobin-like receptors, defensins [59]. CNVs may affect phenotype by altering transcriptional level of genes within or adjacent to CNVR and subsequently alters translation levels. Such transcriptional and translational changes have already been demonstrated $[60,61]$. 


\section{Conclusion}

The chicken genome was examined for chromosomal segmental copy number variations with whole genome tiling arrays. Twenty six high confidence CNVs that were observed in two or more birds and seventy CNVs that were observed once were identified. The majority of the high confidence CNVs was shared across breeds (broiler, Leghorn, and Rhode Island Red). Fifteen CNV loci involve functional genes, or spliced EST coding sequences. Although CNVs that were observed once require further confirmation, some of them represent true CNVs.

The mapping of CNVs in chicken could provide new opportunity for understanding genomic variation and related phenotypic characteristics. This mapping will also contribute to association studies in effort to map traits of economic importance.

\section{Methods}

DNA samples: Blood samples were collected from 3 strains of chickens (Cornish Rock broiler, Leghorn and Rhode Island Red) with $0.5 \mathrm{M}$ EDTA and stored at $-20^{\circ} \mathrm{C}$ until DNA isolation. Leghorn and broiler birds (commercial generation) were purchased from Ideal Poultry (Texas, USA). Rhode Island Red birds were purchased from Murray McMurray Hatchery (Iowa, USA). DNA was isolated with DNeasy genomic DNA isolation kit or phenol chloroform extraction. All DNA samples for array hybridization were analyzed with agarose gel electrophoresis and spectrophotometry. DNA concentrations were measured with NanoDrop spectrophotometer (NanoDrop Technologies, Willmington, DE). Ten samples (4 Leghorns, 4 broilers and 2 Rhode Island Reds) were analyzed with array CGH and twenty three samples were analyzed by qPCR. In addition, a broiler male was used as the reference for all aCGH analysis. The use of animals was approved by Tennessee State University Institutional Animal Care and Use Committee (IACUC).

Hybridization: ACGH was carried out using whole genome tiling array galGal3_WG_CGH. This array platform was designed from the chicken genome build 2.1 from UCSC genome database (2006). The array contained 385,000 probes of $50-75 \mathrm{mer}$. The mean probe spacing was $2557 \mathrm{bp}$ and the median probe spacing was 2586 bp.

Each test DNA sample, labeled with Cy3, was cohybridized with the reference male broiler sample (labeled with Cy5). The hybridization and initial data analysis (normalization and segmentation) were performed by NimbleGen Systems Inc (Madison, WI, USA). Segmentation analysis was performed with NimbleScan 2.4 software (segMNT algorithm). NimbleGen has provided literature package describing the technical specifics http://www.nimblegen.com/products/lit/lit.html. Crite- ria for CNV calls were similar to Chen et al [13] and Graubert et al. [16]. Segments of five or more probes with mean $\log _{2}$ ratio shift from baseline greater than $+/-0.3$ were flagged as candidate CNV. Probes from uncertain chromosomal loci (Chr\#-random and ChrUn-random in the UCSC database) and from W chromosome were removed from the results. Raw aCGH data for this study have been deposited to GenBank GEO database under accession GSE19469 http://www.ncbi.nlm.nih.gov/geo/ query/acc.cgi?acc=GSE19469.

QPCR: PCR primers were designed using Primer Express 2.0 (Applied Biosystems, Carlsbad, CA), Sequences of the primers are available in Additional file 4, Table S2. All qPCR assays were conducted using SYBR GreenER qPCR kit (Invitrogen, Carlsbad, CA). Reaction was done in $20 \mu \mathrm{l}$ containing $20 \mathrm{ng}$ of genomic DNA (approximately 16,000 copies), 0.4 $\mu \mathrm{M}$ of each primer. Thermal cycles were: 1 cycle of pre-incubation at $50^{\circ} \mathrm{C}$ for $2 \mathrm{~min}$ and $95^{\circ} \mathrm{C}$ for $8 \mathrm{~min}, 35$ cycles of amplification $\left(95^{\circ} \mathrm{C}\right.$ for $15 \mathrm{~s}$ and $60^{\circ} \mathrm{C}$ for $60 \mathrm{~s}$ ). Primers were validated by melting curve analysis, amplification analysis, standard curve, and no-template control reactions. For standard curve analysis, one DNA sample was serial diluted to 10 , 20, 40 and $80 \mathrm{ng} / \mu \mathrm{l}$, and measured again with spectrophotometer. Each concentration was analyzed in quadruplicates with qPCR to determine amplification efficiency. These assays showed amplification efficiencies between $112.4 \%$ and $132.7 \%$, and correlation coefficients between 0.971 and 0.990 . For melting curve analysis, PCR product of each primer set showed a single melting peak. Two separate $\mathrm{qPCR}$ assays were performed to determine relative copy numbers for each of three CNV loci (RHACD8, $P R L R$, and $A K R 1 B)$. The first assay tested 23 birds and relative copy numbers were estimated with $2^{-\Delta \mathrm{Ct}}$ method after primer validation. The second assay was done essentially the same way for 20 birds (included in the first assay) except that standard curve was generated concomitantly in the same plate with 4 concentrations $(80,20,10$ and $2.5 \mathrm{ng} / \mu \mathrm{l}$ ) and copy numbers were estimated based on standard curve. Efficiencies of the second qPCR assay were $78.7 \%, 94.8 \%, 91.3 \% 95.7 \%$, for PCCA, RHACD8, $P R L R$ and $A K R 1 B$ loci respectively.

Each test genomic DNA was diluted in Tris-EDTA (10 $\mathrm{mM}$ TRIS- $\mathrm{HCl}, 1 \mathrm{mM}$ EDTA) buffer to $10 \mathrm{ng} / \mu \mathrm{l}$, assessed with qPCR in quadruple reactions. QPCR was performed with iCycler (Bio-Rad, Hercules, CA), 96-well plate (BioRad, cat\# 2239441) and optical adhesive film (Applied Biosystems, Part \# 4311971). To avoid potential uneven heating of reactions at the edge of thermal block, perimeter wells of PCR plates were routinely avoided when possible. In the first qPCR assay, copy numbers were

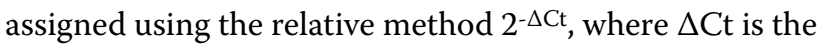
threshold cycle difference between the test sample and an arbitrarily selected reference sample that was used as a 
standard. The reference was considered to have two copies (when the standard is an autosomal locus) or one copy (when a locus is on $\mathrm{Z}$ chromosome of a female). In the second qPCR assay, relative copy numbers were assigned by comparing the $\mathrm{Ct}$ values with standard curve and the amount of copies in $1 \mathrm{ng}$ of reference DNA (assumed as one unit).

RT-qPCR: Spleen of adult broiler and Leghorn was removed immediately after sacrificing birds by cervical dislocation, briefly frozen in liquid nitrogen, and transferred to $-80^{\circ} \mathrm{C}$ until RNA isolation. Total RNA was extracted with RNeasy kit (Qiagen, Valencia, CA). RNA concentration was determined with NanDrop and diluted to $25 \mathrm{ng} / \mu \mathrm{l}$ for transcript level analysis. An EST (GenBank accession CF255001) derived from CNV locus 13 (chr4:88,954,181-88,987,642) was used to design primers for transcript level analysis. RT-qPCR was carried out as described previously [62] with slight modifications using QuantiTect SYBR Green RT-PCR kit (Qiagen). To use iCycler equipment with the RT-PCR kit, fluorescein (BioRad) was added to a final concentration of $10 \mathrm{nM}$. Equipment and plastics were the same as used in QPCR. Each reaction was carried out in 20- $\mu$ l volume containing $50 \mathrm{ng}$ of total RNA and $0.4 \mu \mathrm{M}$ of forward and reverse primers. Reverse transcription was done at $50^{\circ} \mathrm{C}$ for $10 \mathrm{~min}$, followed by 1 cycle of incubation at $90^{\circ} \mathrm{C}$ for $15 \mathrm{~min}$, and then 35 cycles of amplification $\left(95^{\circ} \mathrm{C}\right.$ for $15 \mathrm{~s}$ and $60^{\circ} \mathrm{C}$ for $60 \mathrm{~s}$ ). No amplification product was seen in no-template control reactions. Threshold cycles for no-reverse transcriptase control were at least 7 cycles greater than that for reactions with reverse transcriptase. Similar to qPCR assay on DNA, two separate RT-qPCR assays were conducted for $C D 8 \alpha$ and $R H A C D 8$ : the first one with $2^{-\Delta C t}$ method and the second one with standard curve method. RT-qPCR efficiencies for $C D 8 \alpha$ and $R H A C D 8$ primers, obtained by at least three reproducible standard curve analyses, were $96.3 \% \sim 97.5 \%$ and $80.1 \% \sim 106.2 \%$, respectively, all with correlation coefficient $>0.99$. The second RT-qPCR assay was performed for GAPDH, $\beta$ actin $C D 8 \alpha$ and $R H A C D 8$, concomitantly with standard curve. Efficiencies were 102.1\%, 127.2\%, 85.7\% and 83.9\% respectively. Levels of transcripts were expressed relative to the amount in $1 \mathrm{ng}$ of total RNA in the reference sample.

\section{Additional material}

Additional file 1 Fig. S1: Examples of aCGH plot for 26 high confidence CNV.

Additional file 2 Table S1: CNV loci observed once. Additional file 3 Fig. S2: Examples of likely false negative CNV occurrence.

Additional file 4 Table S2: Primers used in the study.

\section{Abbreviations}

aCGH, array comparative genome hybridization; AKR1B, aldo-keto reductase 1B; CD8a, CD8 antigen alpha chain; aCGH, array comparative genome hybridization; CHRM, cholinergic receptor muscarinic; CNV, copy number variation; CNVR, CNV region; EST, expressed sequence tag; GAPDH, glyceraldehyde 3phosphate dehydrogenase; $\mathrm{Mb}$, million base pair; PCCA, propionyl coenzyme A carboxylase; PCR, polymerase chain reaction; PRLR, prolactin receptor; $q P C R$, quantitative real time $P C R$; $R T-q P C R$, quantitative real time reverse transcriptase-PCR; SNP, single nucleotide polymorphism; THRSP, thyroid hormone responsive spot 14; ZFR, zinc finger RNA binding protein.

\section{Authors' contributions}

XW conceived, designed and performed experiment, analyzed data, wrote the manuscript. SN conceived, designed and performed experiment, analyzed data, wrote the manuscript. TKF performed DNA isolation, qPCR analysis and discussed manuscript. AB performed qPCR, RT-qPCR assay. NA managed animals and collected samples and discussed the manuscript. All authors read and approved the final manuscript, except NA, who passed away during the review

\section{Acknowledgements}

We thank Dr. Philip Ganter for his critical reading and editing of this manuscript. We greatly appreciate Dr. Dafeng Hui's valuable discussion on statistic test. We also thank James Tyus for assistance in sample collection. We are grateful to Dr. Michael Ivy for his contribution of reagent and discussion. We thank Mr. Gregory Coates, Miss Niesha Bonner and Mr. Johnson Anthony for assistance in DNA preparation and qPCR assay. This study was supported in part by TSU faculty research award and USDA grants (2008-38814-04728 and Evans Allen funds).

\section{Author Details}

1Department of Biological Sciences, Tennessee State University, 3500 John A. Merritt Blvd, Nashville, TN 37209, USA and 2Department of Agricultural Sciences, Tennessee State University, 3500 John A. Merritt Blvd, Nashville, TN 37209, USA

Received: 2 July 2009 Accepted: 3 June 2010

Published: 3 June 2010

\section{References}

1. Li J, Jiang T, Mao JH, Balmain A, Peterson L, Harris C, Rao PH, Havlak P, Gibbs R, Cai WW: Genomic segmental polymorphisms in inbred mouse strains. Nat Genet 2004, 36:952-954.

2. Redon $\mathrm{R}$, Ishikawa S, Fitch KR, Feuk L, Perry GH, Andrews TD, Fiegler H, Shapero MH, Carson AR, Chen W, Cho EK, Dallaire S, Freeman JL, Gonzalez JR, Gratacos M, Huang J, Kalaitzopoulos D, Komura D, MacDonald JR, Marshall CR, Mei R, Montgomery L, Nishimura K, Okamura K, Shen F, Somerville MJ, Tchinda J, Valsesia A, Woodwark C, Yang F, et al.: Global variation in copy number in the human genome. Nature 2006, 444:444-454

3. Feuk $L$, Carson AR, Scherer SW: Structural variation in the human genome. Nat Rev Genet 2006, 7:85-97.

4. Komura D, Shen F, Ishikawa S, Fitch KR, Chen W, Zhang J, Liu G, Ihara S, Nakamura H, Hurles ME, Lee C, Scherer SW, Jones KW, Shapero MH, Huang J, Aburatani H: Genome-wide detection of human copy number variations using high-density DNA oligonucleotide arrays. Genome Res 2006, 16:1575-1584.

5. Fiegler $\mathrm{H}$, Redon $\mathrm{R}$, Andrews D, Scott $\mathrm{C}$, Andrews R, Carder C, Clark R, Dovey O, Ellis P, Feuk L, French L, Hunt P, Kalaitzopoulos D, Larkin J, Montgomery L, Perry GH, Plumb BW, Porter K, Rigby RE, Rigler D, Valsesia A, Langford C, Humphray SJ, Scherer SW, Lee C, Hurles ME, Carter NP: Accurate and reliable high-throughput detection of copy number variation in the human genome. Genome Res 2006, 16:1566-1574.

6. Bailey JA, Gu Z, Clark RA, Reinert K, Samonte RV, Schwartz S, Adams MD, Myers EW, Li PW, Eichler EE: Recent segmental duplications in the human genome. Science 2002, 297:1003-1007.

7. Sebat J, Lakshmi B, Troge J, Alexander J, Young J, Lundin P, Maner S, Massa H, Walker M, Chi M, Navin N, Lucito R, Healy J, Hicks J, Ye K, Reiner A, Gilliam TC, Trask B, Patterson N, Zetterberg A, Wigler M: Large-scale copy number polymorphism in the human genome. Science 2004, 305:525-528. 
8. McElroy JP, Nelson MR, Caillier SJ, Oksenberg JR: Copy number variation in African Americans. BMC Genet 2009, 10:15.

9. Glessner JT, Wang K, Cai G, Korvatska O, Kim CE, Wood S, Zhang H, Estes A, Brune CW, Bradfield JP, Imielinski M, Frackelton EC, Reichert J, Crawford EL, Munson J, Sleiman PM, Chiavacci R, Annaiah K, Thomas K, Hou C, Glaberson W, Flory J, Otieno F, Garris M, Soorya L, Klei L, Piven J, Meyer KJ, Anagnostou E, Sakurai T, et al.: Autism genome-wide copy number variation reveals ubiquitin and neuronal genes. Nature 2009, 459:569-573.

10. Wong KK, deLeeuw RJ, Dosanjh NS, Kimm LR, Cheng Z, Horsman DE, MacAulay C, Ng RT, Brown CJ, Eichler EE, Lam WL: A comprehensive analysis of common copy-number variations in the human genome. Am J Hum Genet 2007, 80:91-104.

11. Perry GH, Tchinda J, McGrath SD, Zhang J, Picker SR, Caceres AM, lafrate AJ, Tyler-Smith C, Scherer SW, Eichler EE, Stone AC, Lee C: Hotspots for copy number variation in chimpanzees and humans. Proc Natl Acad Sci USA 2006, 103:8006-8011.

12. Dumas L, Kim YH, Karimpour-Fard A, Cox M, Hopkins J, Pollack JR, Sikela $J M$ : Gene copy number variation spanning 60 million years of human and primate evolution. Genome Res 2007, 17:1266-1277.

13. Chen WK, Swartz JD, Rush LJ, Alvarez CE: Mapping DNA structural variation in dogs. Genome Res 2008, 19:500-509.

14. Nicholas TJ, Cheng Z, Ventura M, Mealey K, Eichler EE, Akey JM: The genomic architecture of segmental duplications and associated copy number variants in dogs. Genome Res 2009, 19:491-499.

15. Snijders AM, Nowak NJ, Huey B, Fridlyand J, Law S, Conroy J, Tokuyasu T, Demir K, Chiu R, Mao JH, Jain AN, Jones SJM, Balmain A, Pinkel D, Albertson DG: Mapping segmental and sequence variations among laboratory mice using BAC array CGH. Genome Res 2005, 15:302-311.

16. Graubert TA, Cahan P, Edwin D, Selzer RR, Richmond TA, Eis PS, Shannon WD, Li X, McLeod HL, Cheverud JM, Ley TJ: A high-resolution map of segmental DNA copy number variation in the mouse genome. PLoS Genet 2007, 3:e3.

17. Egan CM, Sridhar S, Wigler M, Hall IM: Recurrent DNA copy number variation in the laboratory mouse. Nat Genet 2007, 39:1384-1389.

18. She X, Cheng Z, Zollner S, Church DM, Eichler EE: Mouse segmental duplication and copy number variation. Nat Genet 2008, 40:909-914.

19. Guryev V, Saar K, Adamovic T, Verheul M, van Heesch SA, Cook S, Pravenec M, Aitman T, Jacob H, Shull JD, Hubner N, Cuppen E: Distribution and functional impact of DNA copy number variation in the rat. Nat Gene 2008, 40:538-545.

20. Fadista J, Nygaard M, Holm LE, Thomsen B, Bendixen C: A snapshot of CNVs in the pig genome. PLOS ONE 2008, 3:e3916.

21. Ahlroth MK, Ahlroth P, Kulomaa MS: Copy-Number Fluctuation by Unequal Crossing-Over in the Chicken Avidin Gene Family. Biochem Biophys Res Commun 2001, 288:400-406.

22. Delany ME: Patterns of ribosomal gene variation in elite commercial chicken pure line populations. Animal Genetics 2000, 31:110-116.

23. Griffin DK, Robertson LB, Tempest HG, Vignal A, Fillon V, Crooijmans RP, Groenen MA, Deryusheva S, Gaginskaya E, Carre W, Waddington D, Talbot R, Volker M, Masabanda JS, Burt DW: Whole genome comparative studies between chicken and turkey and their implications for avian genome evolution. BMC Genomics 2008, 9:168.

24. Burt DW: Emergence of the chicken as a model organism: implications for agriculture and biology. Poult Sci 2007, 86:1460-1471.

25. Brown WR, Hubbard SJ, Tickle C, Wilson SA: The chicken as a model for large-scale analysis of vertebrate gene function. Nat Rev Genet 2003, 4:87-98.

26. Duriez B, Sobrier ML, Duquesnoy P, Tixier-Boichard M, Decuypere E, Coquerelle G, Zeman M, Goossens M, Amselem S: A naturally occurring growth hormone receptor mutation: in vivo and in vitro evidence for the functional importance of the WS motif common to all members of the cytokine receptor superfamily. Mol Endocrinol 1993, 7:806-814.

27. Burnside J, Liou SS, Zhong C, Cogburn LA: Abnormal growth hormone receptor gene expression in the sex-linked dwarf chicken. Gen Comp Endocrinol 1992, 88:20-28.

28. Semple-Rowland SL, Lee NR, Van Hooser JP, Palczewski K, Baehr W: A null mutation in the photoreceptor guanylate cyclase gene causes the retinal degeneration chicken phenotype. Proc Natl Acad Sci USA 1998, 95:1271-1276

29. Zarucki-Schulz T, Tsai SY, Itakura K, Soberon X, Wallace RB, Tsai MJ, Woo SL, O'Malley BW: Point mutagenesis of the ovalbumin gene promoter sequence and its effect on in vitro transcription. J Biol Chem 1982 257:11070-11077

30. Wang LH, Tsai SY, Cook RG, Beattie WG, Tsai MJ, O'Malley BW: COUP transcription factor is a member of the steroid receptor superfamily. Nature 1989, 340:163-166.

31. Tsai SY, Tsai MJ: Chick ovalbumin upstream promoter-transcription factors (COUP-TFs): coming of age. Endocr Rev 1997, 18:229-240.

32. Consortium ICGS: Sequence and comparative analysis of the chicken genome provide unique perspectives on vertebrate evolution. Nature 2004, 432:695-716.

33. Wong GK, Liu B, Wang J, Zhang Y, Yang X, Zhang Z, Meng Q, Zhou J, Li D, Zhang J, Ni P, Li S, Ran L, Li H, Li R, Zheng H, Lin W, Li G, Wang X, Zhao W, Li J, Ye C, Dai M, Ruan J, Zhou Y, Li Y, He X, Huang X, Tong W, Chen J, et al.: A genetic variation map for chicken with 2.8 million single-nucleotide polymorphisms. Nature 2004, 432:717-722.

34. Abdrakhmanov I, Lodygin D, Geroth P, Arakawa H, Law A, Plachy J, Korn B, Buerstedde JM: A large database of chicken bursal ESTs as a resource for the analysis of vertebrate gene function. Genome Res 2000, 10:2062-2069

35. Tirunagaru VG, Sofer L, Cui J, Burnside J: An expressed sequence tag database of T-cell-enriched activated chicken splenocytes: sequence analysis of 5251 clones. Genomics 2000, 66:144-151.

36. Boardman PE, Sanz-Ezquerro J, Overton IM, Burt DW, Bosch E, Fong WT, Tickle C, Brown WR, Wilson SA, Hubbard SJ: A comprehensive collection of chicken cDNAs. Curr Biol 2002, 12:1965-1969.

37. Carre W, Wang X, Porter TE, Nys Y, Tang J, Bernberg E, Morgan R, Burnside J, Aggrey SE, Simon J, Cogburn LA: Chicken genomics resource: sequencing and annotation of 35,407 ESTs from single and multiple tissue CDNA libraries and CAP3 assembly of a chicken gene index. Physiol Genomics 2006, 25:514-524.

38. Cogburn LA, Wang X, Carre W, Rejto L, Aggrey SE, Duclos MJ, Simon J, Porter TE: Functional genomics in chickens: development of integrated-systems microarrays for transcriptional profiling and discovery of regulatory pathways. Comp Funct Genomics 2004, 5:253-261.

39. Burnside J, Neiman P, Tang J, Basom R, Talbot R, Aronszajn M, Burt D, Delrow J: Development of a cDNA array for chicken gene expression analysis. BMC Genomics 2005, 6:13.

40. Li X, Chiang HI, Zhu J, Dowd SE, Zhou H: Characterization of a newly developed chicken 44K Agilent microarray. BMC Genomics 2008, 9:60

41. Shibusawa M, Nishibori M, Nishida-Umehara C, Tsudzuki M, Masabanda J, Griffin DK, Matsuda Y: Karyotypic evolution in the Galliformes: an examination of the process of karyotypic evolution by comparison of the molecular cytogenetic findings with the molecular phylogeny. Cytogenet Genome Res 2004, 106:111-119.

42. Federico C, Cantarella CD, Scavo C, Saccone S, Bed'Hom B, Bernardi G: Avian genomes: different karyotypes but a similar distribution of the GC-richest chromosome regions at interphase. Chromosome Res 2005 13:785-793

43. Wang X, Li J, Leung FC: Partially inverted tandem repeat isolated from pericentric region of chicken chromosome 8. Chromosome Res 2002, 10:73-82.

44. Masabanda JS, Burt DW, O'Brien PC, Vignal A, Fillon V, Walsh PS, Cox H, Tempest HG, Smith J, Habermann F, Schmid M, Matsuda Y, FergusonSmith MA, Crooijmans RP, Groenen MA, Griffin DK: Molecular cytogenetic definition of the chicken genome: the first complete avian karyotype. Genetics 2004, 166:1367-1373.

45. Wahlberg P, Stromstedt L, Tordoir X, Foglio M, Heath S, Lechner D, Hellstrom AR, Tixier-Boichard M, Lathrop M, Gut IG, Andersson L: A highresolution linkage map for the $Z$ chromosome in chicken reveals hot spots for recombination. Cytogenet Genome Res 2007, 117:22-29.

46. Wang X, Carre W, Zhou H, Lamont SJ, Cogburn LA: Duplicated Spot 14 genes in the chicken: characterization and identification of polymorphisms associated with abdominal fat traits. Gene 2004, 332:79-88.

47. Elferink MG, Vallee AA, Jungerius AP, Crooijmans RP, Groenen MA: Partial duplication of the PRLR and SPEF2 genes at the late feathering locus in chicken. BMC Genomics 2008, 9:391

48. Liaw HJ, Chen WR, Huang YC, Tsai CW, Chang KC, Kuo CL: Genomic organization of the chicken CD8 locus reveals a novel family of immunoreceptor genes. J Immunol 2007, 178:3023-3030. 
49. Wess J: Molecular basis of muscarinic acetylcholine receptor function. Trends Pharmacol Sci 1993, 14:308-313.

50. Barski OA, Tipparaju SM, Bhatnagar A: The aldo-keto reductase superfamily and its role in drug metabolism and detoxification. Drug Metab Rev 2008, 40:553-624.

51. Spite M, Baba SP, Ahmed Y, Barski OA, Nijhawan K, Petrash JM, Bhatnagar A, Srivastava S: Substrate specificity and catalytic efficiency of aldo-keto reductases with phospholipid aldehydes. Biochem J 2007, 405:95-105.

52. Tirard J, Gout J, Lefrancois-Martinez AM, Martinez A, Begeot M, Naville D: A novel inhibitory protein in adipose tissue, the aldo-keto reductase AKR1B7: its role in adipogenesis. Endocrinology 2007, 148:1996-2005.

53. Ma J, Yan R, Zu X, Cheng JM, Rao K, Liao DF, Cao D: Aldo-keto reductase family $1 \mathrm{~B} 10$ affects fatty acid synthesis by regulating the stability of acetyl-CoA carboxylase-alpha in breast cancer cells. J Biol Chem 2008, 283:3418-3423.

54. Lee AS, Gutierrez-Arcelus M, Perry GH, Vallender EJ, Johnson WE, Miller GM, Korbel JO, Lee C: Analysis of copy number variation in the rhesus macaque genome identifies candidate loci for evolutionary and human disease studies. Hum Mol Genet 2008, 17:1127-1136.

55. Pinto D, Marshall C, Feuk L, Scherer SW: Copy-number variation in control population cohorts. Hum Mol Genet 2007, 16:R168-173.

56. Conrad DF, Andrews TD, Carter NP, Hurles ME, Pritchard JK: A highresolution survey of deletion polymorphism in the human genome. Nat Genet 2006, 38:75-81.

57. Perry GH, Ben-Dor A, Tsalenko A, Sampas N, Rodriguez-Revenga L, Tran CW, Scheffer A, Steinfeld I, Tsang P, Yamada NA, Park HS, Kim JI, Seo JS, Yakhini Z, Laderman S, Bruhn L, Lee C: The fine-scale and complex architecture of human copy-number variation. Am J Hum Genet 2008, 82:685-695.

58. Smith AJd, Tsalenko A, Sampas N, Scheffer A, Yamada NA, Tsang P, BenDor A, Yakhini Z, Ellis RJ, Bruhn L, Laderman S, Froguel P, Blakemore Al: Array CGH analysis of copy number variation identifies 1284 new genes variant in healthy white males: implications for association studies of complex diseases. Hum Mol Genet 2007, 16:2783-2794

59. Freeman $\mathrm{JL}$, Perry GH, Feuk L, Redon R, McCarroll SA, Altshuler DM, Aburatani H, Jones KW, Tyler-Smith C, Hurles ME, Carter NP, Scherer SW, Lee C: Copy number variation: new insights in genome diversity. Genome Res 2006, 16:949-961.

60. Aldred PM, Hollox EJ, Armour JA: Copy number polymorphism and expression level variation of the human alpha-defensin genes DEFA1 and DEFA3. Hum Mol Genet 2005, 14:2045-2052.

61. Perry GH, Dominy NJ, Claw KG, Lee AS, Fiegler H, Redon R, Werner J, Villanea FA, Mountain JL, Misra R, Carter NP, Lee C, Stone AC: Diet and the evolution of human amylase gene copy number variation. Nat Genet 2007, 39:1256-1260.

62. Wang X, Newkirk RF, Carre W, Ghose P, Igobudia B, Townsel JG, Cogburn LA: Regulation of ANKRD9 expression by lipid metabolic perturbations. BMB Reports 2009, 42:568-573.

doi: 10.1186/1471-2164-11-351

Cite this article as: Wang et al., An initial map of chromosomal segmental copy number variations in the chicken BMC Genomics 2010, 11:35

\section{Submit your next manuscript to BioMed Central} and take full advantage of:

- Convenient online submission

- Thorough peer review

- No space constraints or color figure charges

- Immediate publication on acceptance

- Inclusion in PubMed, CAS, Scopus and Google Scholar

- Research which is freely available for redistribution

Submit your manuscript at www.biomedcentral.com/submit
C Biomed Central 